\title{
Mecanismos utilizados pelos destinatários do discurso para identificação de relações de coerência não sinalizadas por conectores ${ }^{*}$ \\ Means used by discourse addressees for the identification of coherence relations not signaled by discourse markers
}

Juliano Desiderato ANTONIO

(Universidade Estadual de Maringá - UEM)

RESUMO

Este trabalho tem como objetivo apresentar outros mecanismos de sinalização das relações retóricas (ou relações de coerência) além de conectores utilizados pelos destinatários do discurso para identificação das relações. A investigação, baseada na Teoria da Estrutura Retórica, foi realizada a partir da apresentação de dez excertos para professores de curso superior para que se pudesse verificar se a relação retórica estabelecida entre as porções textuais que compõem o excerto foi reconhecida. Em sua grande maioria, as relações retóricas foram identificadas pelos informantes. As pistas indicadas pelos informantes foram formais, fonológicas, morfossintáticas, semânticas, textuais e cognitivas.

Palavras-chave: Funcionalismo; Teoria da Estrutura Retórica; Relações de Coerência; Relações Retóricas.

*. Este trabalho apresenta resultados de projeto de pesquisa financiado pela Fundação Araucária (Convênio 477/2014). Colaboraram com a pesquisa as acadêmicas Camila Cristiane Moreschi (PIC-UEM) e Virgínia Maria Nuss (PIBIC-UEM/Cnpq). 


\begin{abstract}
The aim of this paper is to present other means of signaling rhetorical relations (or coherence relations) rather than connectives used by discourse addressees to identify the relations. The investigation, based on Rhetorical Structure Theory, was held by the presentation of ten excerpts to university professors in order to verify if the rhetorical relation held between the texts spans that comprise the excerpt could be identified. Most of the relations were successfully identified by the informants, and the signals used for the identification were formal, phonological, morphosyntactic, semantic, textual and cognitive.
\end{abstract}

Key-words: Functionalism; Rhetorical Structure Theory; Coherence Relations; Rhetorical Relations.

\title{
Introdução
}

A coerência textual pode ser avaliada, segundo Sanders, Spooren, \& Noordman (1992), levando-se em conta dois aspectos: o conteúdo das porções de texto ou as relações estabelecidas entre duas ou mais porções de texto. No primeiro caso, a coerência é obtida por meio da continuidade tópica ou referencial (Givón, 1983; van Dijk \& Kintsch, 1983), por meio da congruência semântica entre as porções de texto (Polanyi, 1986) ou por meio da representação de padrões correspondentes a situações e eventos prototípicos no mundo representado no texto (Schank \& Abelson, 1977). No segundo caso, levam-se em conta as relações estabelecidas entre segmentos adjacentes na microestrutura textual (como orações, por exemplo, ou unidades de entonação, na língua falada, de acordo com Chafe (1985), ou entre segmentos de níveis mais altos (como porções de texto que atuam na macroestrutura textual, de acordo com (van Dijk, 1992). Essas relações têm recebido várias denominações nos estudos linguísticos: predicados retóricos (Grimes, 1975), proposições relacionais (Mann \& Thompson, 1983), relações de coerência (Hobbs, 1985), relações retóricas (Mann \& Thompson, 1988) ${ }^{1}$.

1. Neste trabalho, os termos relações retóricas e relações de coerência serão utilizados como equivalentes. 
O tratamento da coerência que interessa a esta pesquisa é o que diz respeito às relações entre duas ou mais porções de texto. Um tratamento adequado a essa questão das relações de coerência é oferecido pela RST (Rhetorical Structure Theory - Teoria da Estrutura Retórica), uma teoria descritiva que tem por objeto o estudo da organização dos textos, caracterizando as relações que se estabelecem entre as partes do texto (Mann, Matthiessen, \& Thompson, 1992; Mann \& Thompson, 1988; Matthiessen \& Thompson, 1988).

Partindo-se do pressuposto de que nem toda relação entre partes do texto ou entre orações é sinalizada por algum tipo de conector, a pergunta que se pretende responder com este trabalho é a seguinte: se há outros meios de sinalização das relações além de conectores, que mecanismos são utilizados pelos destinatários do discurso para identificação dessas relações? O trabalho também objetiva investigar se os informantes encontram dificuldade na identificação das relações de coerência não sinalizadas por conectores.

Deve-se observar que as palavras que funcionam como conectores não formam uma classe homogênea. Na tradição gramatical, essa função é atribuída à classe das conjunções. No entanto, há outros tipos de palavras que estabelecem relações entre orações e entre partes de um texto. Neste trabalho, investigam-se não apenas as conjunções, mas também marcadores discursivos (doravante MDs). O conceito de MDs adotado neste trabalho é o proposto por Risso, Silva e Urbano (2006: 403)

Trata-se de um amplo grupo de elementos de constituição bastante diversificada, envolvendo, no plano verbal, sons não lexicalizados, palavras, locuções e sintagmas mais desenvolvidos, aos quais se pode atribuir homogeneamente a condição de uma categoria pragmática bem consolidada no funcionamento da linguagem.

\section{Fundamentação Teórica}

\section{Teoria da Estrutura Retórica}

A RST parte do princípio de que as relações retóricas que se estabelecem no nível discursivo organizam desde a coerência dos textos até a combinação entre orações (Matthiessen \& Thompson, 1988). 
Ao tratar das relações retóricas tanto no nível discursivo quanto no nível gramatical (combinação entre orações), a RST demonstra sua filiação à Linguística Funcional, um grupo de teorias que consideram essencial para o estudo da língua a função dos elementos linguísticos na comunicação (Butler, 2003; Neves, 1997; Nichols, 1984). Podem ser observados na RST, de acordo com Antonio (2009), pressupostos de outros modelos funcionalistas:

a) o modelo de análise top-down da Gramática Sistêmico-Funcional de Halliday, partindo do texto para os níveis mais baixos da estrutura gramatical (Van Valin, 2002);

b) a motivação discursiva da gramática, observada nos trabalhos dos pesquisadores que compõem o grupo conhecido como Funcionalismo da Costa-Oeste dos EUA, dentre os quais podem ser destacados alguns trabalhos, como Hopper \& Thompson (1980), Givón (1983), Du Bois (1987), dentre outros.

Uma lista de vinte e cinco relações foi estabelecida por Mann \& Thompson (1988) após a análise de centenas de textos, por meio da RST. Essa lista não representa um rol fechado, mas um grupo de relações suficiente para descrever a maioria dos textos ${ }^{2}$.

No que diz respeito à organização, as relações podem ser de dois tipos:

a) núcleo-satélite, nas quais uma porção do texto (satélite) é ancilar da outra (núcleo), como na figura 1 a seguir, em que um arco vai da porção que serve de subsídio para a porção que funciona como núcleo.

b) multinucleares, nas quais uma porção do texto não é ancilar da outra, sendo cada porção um núcleo distinto, como na figura 2 a seguir.

2. Uma lista com as relações e suas definições pode ser encontrada no site http://www. sfu.ca/rst/07portuguese/definitions.html. 


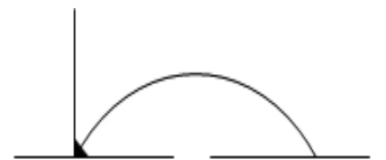

Figura 1 - Esquema de relação núcleo-satélite.

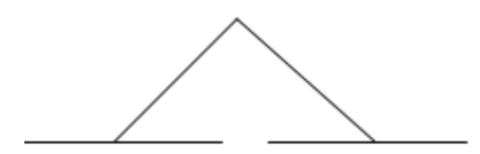

Figura 2 - Esquema de relação multinuclear.

As relações são definidas pela RST com base em quatro condições: a) restrições sobre o núcleo; b) restrições sobre o satélite; c) restrições sobre a combinação entre o núcleo e o satélite; d) efeito. Tome-se como exemplo a definição da relação elaboração apresentada no quadro 1 a seguir.

Quadro 1 - Definição da relação de elaboração (Mann \& Taboada, 2010)

\begin{tabular}{|c|c|c|c|}
\hline $\begin{array}{l}\text { Nome da } \\
\text { relação }\end{array}$ & $\begin{array}{l}\text { Restrições sobre } \\
\text { o núcleo ou } \\
\text { sobre o satélite } \\
\text { individualmente }\end{array}$ & $\begin{array}{l}\text { Restrições sobre núcleo + } \\
\text { satélite }\end{array}$ & $\begin{array}{l}\text { Intenção do } \\
\text { falante }\end{array}$ \\
\hline Elaboração & Nenhuma & $\begin{array}{l}\text { O satélite apresenta detalhes } \\
\text { adicionais sobre a situação } \\
\text { ou sobre algum elemento do } \\
\text { assunto que é apresentado no } \\
\text { núcleo ou é acessível inferen- } \\
\text { cialmente no núcleo em uma } \\
\text { ou mais das maneiras listadas } \\
\text { a seguir. Na lista, se o núcleo } \\
\text { apresenta o primeiro mem- } \\
\text { bro de qualquer par, então o } \\
\text { satélite inclui o segundo. } \\
\text { grupo :: membro } \\
\text { abstração :: instância } \\
\text { todo :: parte } \\
\text { processo :: passo } \\
\text { objeto :: atributo } \\
\text { generalização :: específico. }\end{array}$ & $\begin{array}{l}\text { O destinatário re- } \\
\text { conhece o satélite } \\
\text { como fornecendo } \\
\text { detalhes adicionais } \\
\text { para o núcleo. O } \\
\text { destinatário iden- } \\
\text { tifica o elemento } \\
\text { do assunto para o } \\
\text { qual o detalhe é } \\
\text { fornecido. }\end{array}$ \\
\hline
\end{tabular}

Como pode ser observado na definição, o uso da relação de elaboração tem por objetivo o acréscimo de informações, no satélite, a respeito do núcleo. Isso pode ser observado no diagrama arbóreo a seguir, que representa a análise da estrutura retórica de um trecho de uma aula. 


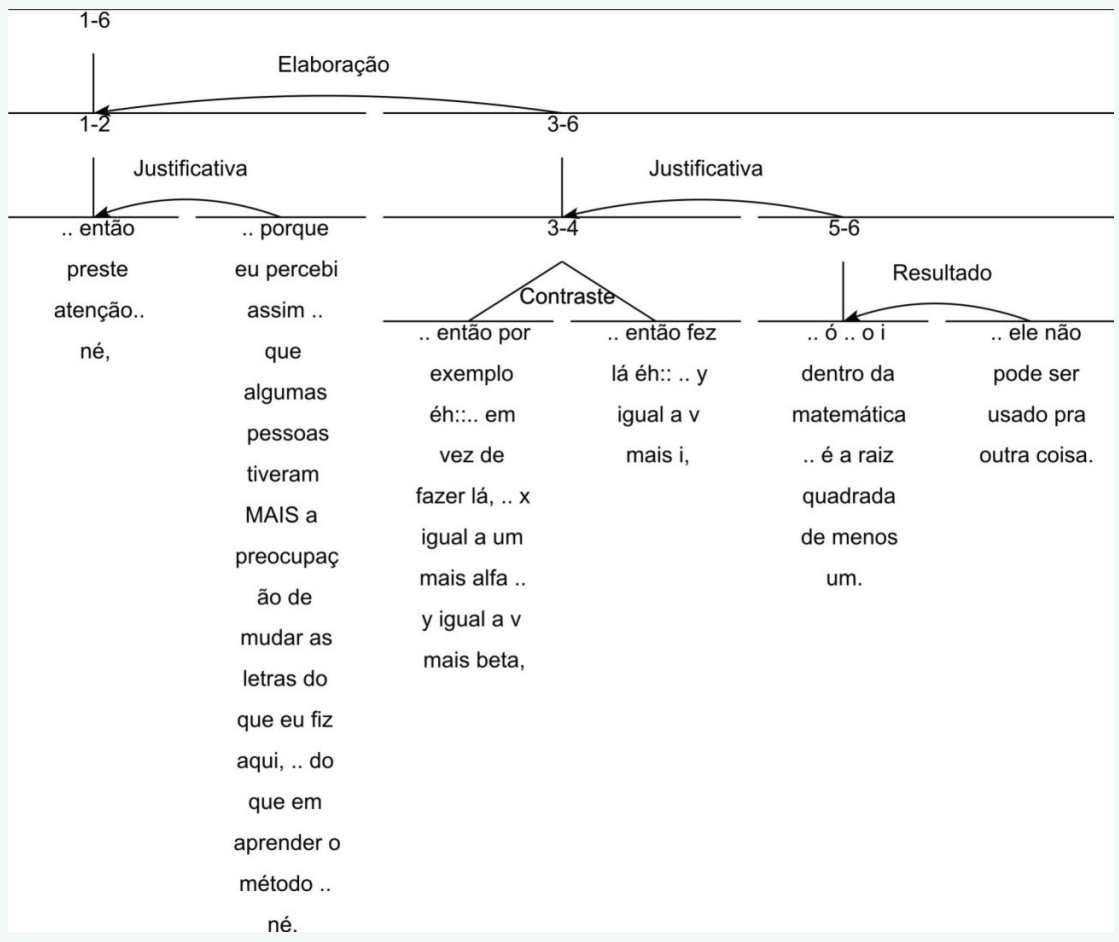

Diagrama 1 - Exemplo da relação de elaboração.

No exemplo, a porção de texto formada pelas unidades de 3 a 6 acrescenta detalhes ao conteúdo do núcleo, formado pelas unidades 1 e 2. Na unidade 1, o professor pede que os alunos prestem atenção. $\mathrm{Na}$ unidade 2, justifica seu ato de fala, afirmando que percebeu que alguns alunos demonstraram mais preocupação em trocar as letras da expressão matemática do que em aprender o método. Nas unidades 3 e 4, o professor, por meio da relação de contraste, apresenta a maneira correta e a maneira errada de resolver a expressão. Em seguida, nas unidades 5 e 6, justifica por que alguns alunos utilizaram uma variável de forma equivocada na expressão. Por fim, o informante apresenta o conteúdo da unidade 5 como motivo para o conteúdo apresentado na unidade 6 , ou seja, o "i" não pode ser usado para representar, na matemática, outra coisa além do valor da raiz quadrada de menos um. 
A análise da estrutura retórica desse trecho demonstra a importância do reconhecimento da proposição relacional de elaboração para o estabelecimento da coerência de texto. Caso o interlocutor do produtor do texto não perceba que as porções textuais que funcionam como satélite estão acrescentando informações a respeito do "assunto" em pauta, não conseguirá calcular a coerência do texto.

De acordo com a RST, as relações de coerência são implícitas e, portanto, são de sentido, e não de forma (Mann \& Thompson, 1983), ou seja, as relações são estabelecidas e interpretadas independentemente de serem marcadas explicitamente por conectivos. Essas relações podem ser descritas com base na intenção comunicativa do enunciador e na avaliação que o enunciador faz do enunciatário, e refletem as escolhas do enunciador para organizar e apresentar os conceitos. A identificação dessas relações pelo analista, por sua vez, se baseia em julgamentos funcionais e semânticos, que buscam identificar a função de cada porção de texto, e verificar como o texto produz o efeito desejado em seu possível receptor.

Esses julgamentos são de plausibilidade, pois o analista tem acesso ao texto, tem conhecimento do contexto em que o texto foi produzido e das convenções culturais do produtor do texto e de seus possíveis receptores, mas não tem acesso direto ao produtor do texto ou aos seus possíveis receptores, de forma que não pode afirmar com certeza que esta ou aquela análise é a correta, mas pode sugerir uma análise plausível (Mann \& Thompson, 1988).

Pesquisas realizadas no sentido de identificar os meios linguísticos utilizados pelos falantes para a sinalização das relações (GómezGonzález \& Taboada, 2005; Taboada, 2006, 2009) têm demonstrado que alguns dos meios mais utilizados são os conectivos e os marcadores discursivos (MDs). Outros meios de sinalização sugeridos por essas autoras são marcas morfológicas, sintáticas, gráficas, de entonação (no caso da língua falada), de referência textual, do gênero textual etc. Em sua pesquisa a respeito da relação de contraste em diálogos, Ford (2000) observou que o significado das porções de texto também pode ser útil na identificação das relações. 


\section{Metodologia}

A investigação foi realizada a partir da apresentação de dez excertos para professores de curso superior. Para cada excerto apresentado, os informantes responderam algumas perguntas para que se pudesse verificar se a relação retórica estabelecida entre as porções textuais que compõem o excerto foi reconhecida.

Os excertos foram retirados do corpus de pesquisa do Grupo de Pesquisas Funcionalistas do Norte/Noroeste do Paraná (Funcpar), constituído por elocuções formais (aulas) e entrevistas. A escolha dos excertos não se deu de forma aleatória. Foram selecionados excertos que contemplassem diferentes tipos de relações retóricas.

Por se tratar de um corpus de língua falada, as porções de texto apresentadas para os informantes da pesquisa foram retextualizadas, ou seja, retiraram-se as marcas do processo de produção oral (Marcuschi, 2001), como pode ser observado no exemplo a seguir.

.. a heterotrófica diz que eles NÃO produziam porque NÃO tinham uma maquinária celular .. suficiente pra produzir seu próprio alimento, .. a autotrófica diz QUE .. não tinha alimento suficiente, .. dai eles tiveram que produzir o seu próprio alimento.

Após retextualizada, essa porção textual ficou com o seguinte formato:

A teoria heterotrófica diz que os primeiros seres vivos não produziam seu próprio alimento porque não tinham uma maquinaria celular suficiente. A teoria autotrófica diz que não havia alimento suficiente, dai os primeiros seres vivos tiveram que produzir seu próprio alimento.

A escolha de professores de curso superior como informantes se justifica pelo fato de as elocuções formais do corpus terem esse público como produtor. Tentou-se, dessa forma, evitar que a falta de informação pragmática fosse um fator que atrapalhasse a compreensão das porções de texto apresentadas aos informantes. 
Nos dez excertos apresentados aos informantes, as relações retóricas não são sinalizadas por conectores, mas por outros meios, como pontuação, correlação modo-temporal, conteúdo das porções textuais, paralelismo sintático, paráfrase, inserção parentética, repetição, apresentação de evidências etc, com a finalidade de verificar se os informantes reconheceriam essas relações por meio dessas outras pistas.

Procurou-se verificar se a falta de sinalização por meio de um conector impediria ou dificultaria a identificação da relação e também se os informantes saberiam explicitar outros meios além dos conectivos que servissem como pista para identificação da relação. A pergunta feita aos informantes foi: "Que relação de sentido há entre os enunciados 'A teoria heterotrófica diz que os primeiros seres vivos não produziam seu próprio alimento porque não tinham uma maquinaria celular suficiente' e 'a teoria autotrófica diz que não havia alimento suficiente, daí os primeiros seres vivos tiveram que produzir seu próprio alimento'?’. Uma outra pergunta também foi feita para tentar verificar que meios foram mobilizados pelos informantes para identificação da relação. A pergunta foi a seguinte: "O que ajudou você a identificar essa relação?".

\section{Resultados e Discussão}

\section{Excerto 1}

(1) A teoria heterotrófica diz que os primeiros seres vivos não produziam seu próprio alimento porque não tinham uma maquinaria celular suficiente.

(2) A teoria autotrófica diz que não havia alimento suficiente, daí os primeiros seres vivos tiveram que produzir seu próprio alimento.

No excerto 1, a relação de contraste se estabelece entre as porções de texto, como pode ser observado no diagrama 2. A relação retórica de contraste (quadro 2) é multinuclear, e sua ocorrência nunca é com mais de dois núcleos. No caso do excerto 1 , o falante se utiliza do paralelismo para contrastar as diferenças entre as teorias heterotrófica e autotrófica. 


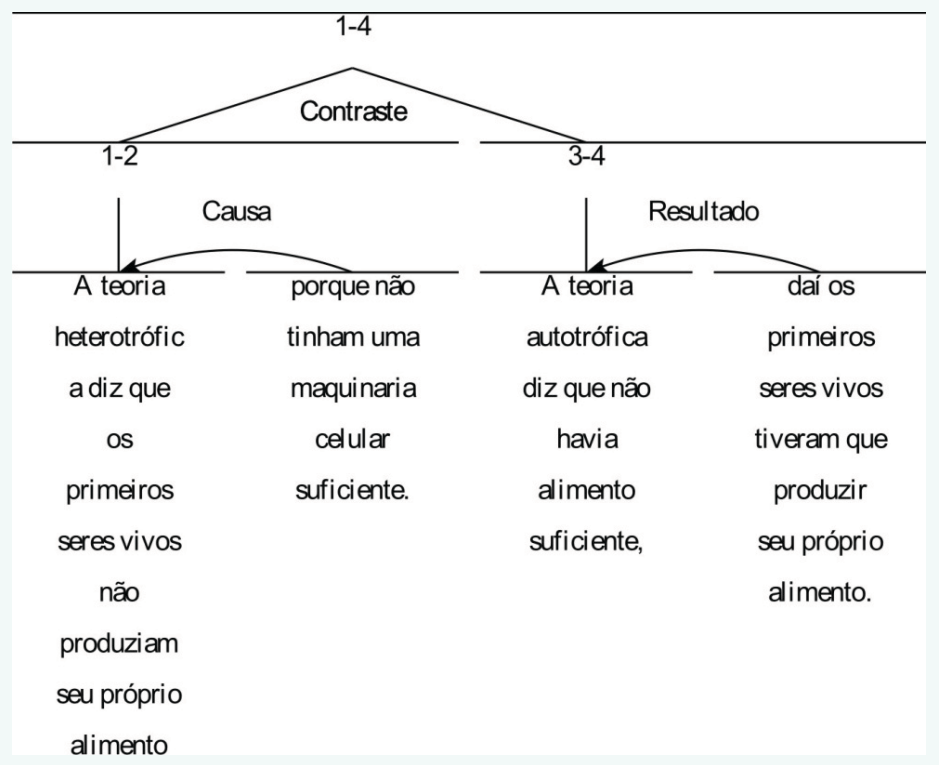

Diagrama 2 - Relação de contraste.

Quadro 2 - Definição da relação de contraste (Mann \& Taboada, 2010)

\begin{tabular}{|l|l|l|}
\hline $\begin{array}{l}\text { Nome da } \\
\text { relação }\end{array}$ & Restrições sobre cada par de núcleos & Intenção do falante \\
\hline Contraste & $\begin{array}{l}\text { Não mais do que dois núcleos; as situações } \\
\text { nesses núcleos são (a) compreendidas como } \\
\text { semelhantes em vários aspectos; (b) compreen- } \\
\text { didas como diferindo em alguns aspectos e (c) } \\
\text { comparado com respeito a uma ou mais dessas } \\
\text { diferenças. }\end{array}$ & $\begin{array}{l}\text { O deco reconhe- } \\
\text { ce comparabilidade e } \\
\text { pela comparação sendo } \\
\text { feita. }\end{array}$ \\
\hline
\end{tabular}

Todos os informantes identificaram corretamente a relação de contraste entre os núcleos. Quando questionados a respeito das pistas utilizadas para identificação da relação, oito informantes apontaram o conteúdo antagônico das porções textuais. Em estudo a respeito da relação de contraste no inglês, Ford (2000) verificou que o significado das palavras e o próprio conteúdo do texto são pistas para sinalizar essa relação. Os outros dois informantes apontaram sinais mais formais: o paralelismo das porções textuais que se contradizem e os prefixos autoe hetero-, que formam as palavras autotrófico e heterotrófico. 


\section{Excerto 2}

(1) Quais os motivos dessas variações entre os indivíduos de uma mesma espécie? São três pontos:

(2) O primeiro ponto importante é a mutação, o segundo ponto é a recombinação gênica e o terceiro ponto é a seleção natural.

No excerto 2, a relação de elaboração (cf. definição no quadro 1, apresentado anteriormente neste trabalho) emerge da combinação entre as porções de texto, como pode ser observado no diagrama 3. O uso da relação de elaboração tem por objetivo o acréscimo de informações, no satélite, a respeito do núcleo. As unidades de 3 a 5 expandem o conteúdo do núcleo, enumerando os três pontos mencionados pelo professor, na unidade 2 , como resposta à pergunta retórica feita por ele mesmo na unidade 1.

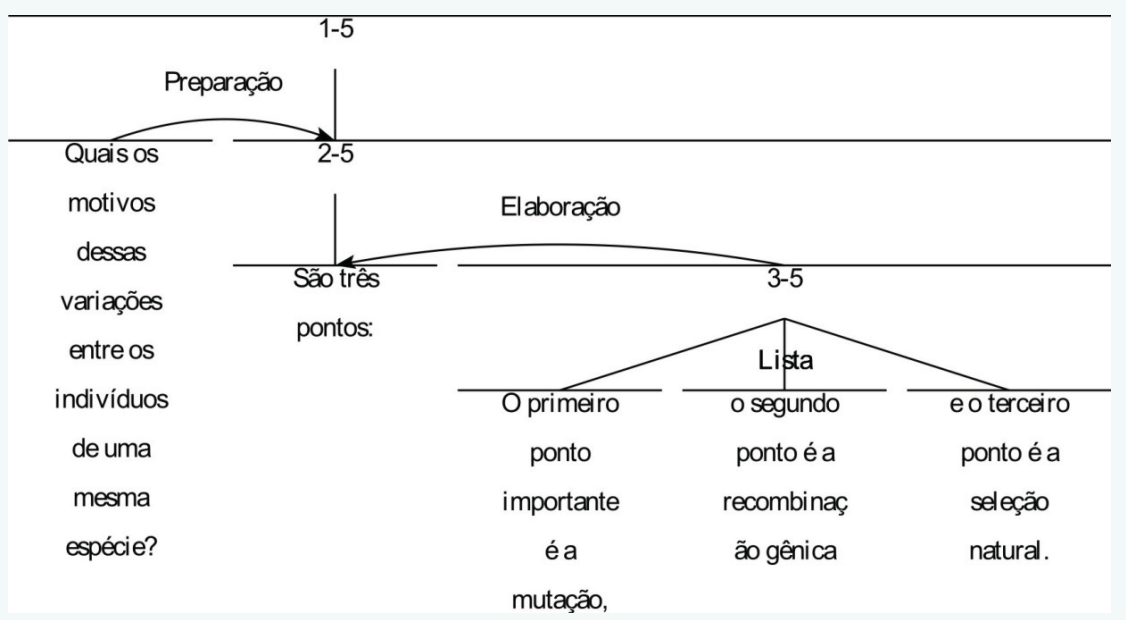

Diagrama 3 - Relação de elaboração.

Todos os informantes identificaram a função de acréscimo de informação, expansão do núcleo pelo satélite. Ao serem questionados sobre a pista que ajudou na identificação da relação, cinco informantes mencionaram o sinal de pontuação (dois pontos). Desses cinco informantes, um utilizou, além da pontuação, a pergunta retórica no início do excerto, e outro informante leu o excerto com uma pausa após os dois pontos. De acordo com Taboada (2009), na língua escrita, os sinais 
de pontuação são um mecanismo muito relevante na identificação das relações. Utilizando um critério prosódico, um informante leu o excerto em voz alta (uma vez que se tratava de trecho de aula) e se baseou na entonação de sua leitura para a identificação. Um informante disse ter se baseado no par pergunta (retórica)-resposta para identificar a relação e, por fim, três informantes se pautaram no anúncio de que "três pontos" seriam enumerados.

Excerto 3

(1) Quando falamos em pecuária, não podemos pensar somente em bois. Pecuária é tudo.

Ovelha é pecuária?

Exato. Búfalo, cavalo, tudo isso é pecuária. Eu tenho os ovinos, eu tenho os caprinos, eu tenho os bovinos, eu tenho os suínos.

(2) Tudo isso aí é pecuária.

No excerto 3, a relação de resumo emerge da combinação entre as porções de texto, como pode ser observado no diagrama 4. Na relação de resumo, o satélite traz uma reformulação abreviada do conteúdo do núcleo (cf. quadro 3). No diagrama 4, o professor resume, na unidade 13, o que foi explicado nas unidades de 1 a 12, ou seja, todos os animais que estão incluídos na pecuária. A relação de resumo é muito utilizada nas aulas pelos professores para retomar as informações apresentadas, reafirmando-as de maneira resumida e, ao mesmo tempo, destacando para os alunos, seus enunciatários, a importância da informação.

Quadro 3 - Definição da relação de resumo

\begin{tabular}{|l|l|l|l|}
\hline $\begin{array}{l}\text { Nome da } \\
\text { relação }\end{array}$ & $\begin{array}{l}\text { Restrições sobre } \\
\text { o núcleo ou } \\
\text { sobre o satélite } \\
\text { individualmente }\end{array}$ & $\begin{array}{l}\text { Restrições sobre } \\
\text { núcleo + satélite }\end{array}$ & Intenção do falante \\
\hline Resumo & $\begin{array}{l}\text { Sobre N: N deve ser } \\
\text { mais do que uma } \\
\text { unidade }\end{array}$ & $\begin{array}{l}\text { S apresenta uma } \\
\text { reformulação do } \\
\text { conteúdo de N, com } \\
\text { um peso inferior }\end{array}$ & $\begin{array}{l}\text { O destinatário reco- } \\
\text { nhece S como uma } \\
\text { reformulação mais } \\
\text { abreviada de N }\end{array}$ \\
\hline
\end{tabular}




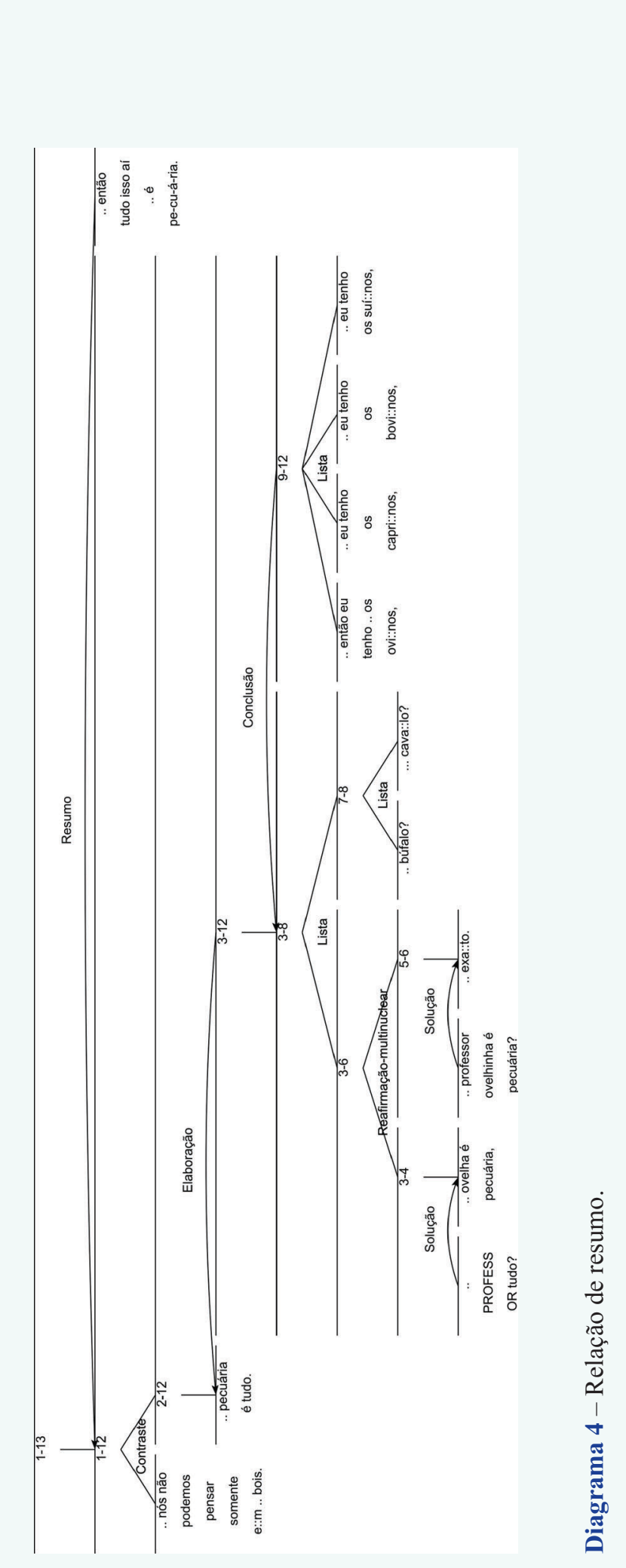

33.1
2017 
Todos os informantes identificaram que há alguma informação a ser ressaltada, seja na forma resumida, sintetizada, seja na forma de uma conclusão. Alguns autores postulam que resumo e conclusão sejam relações que se aproximam semanticamente. A relação de conclusão não faz parte do rol de relações proposto inicialmente pelos autores da RST, mas foi definida posteriormente por Pardo (2005). Pode-se hipotetizar que, antes da definição dessa relação, muitas das ocorrências de conclusão eram anotadas como sendo de resumo. Partindo da perspectiva de outra teoria funcionalista, a Gramática Discursivo Funcional - GDF (Hengeveld \& Mackenzie, 2008), Novaes-Marques (2014) também propõe que resumo e conclusão estão relacionadas, e que o resumo é uma função sob o escopo da relação de conclusão.

Quando questionados a respeito das pistas utilizadas para a identificação da relação, cinco informantes afirmaram que se valeram da referência anafórica realizada pela expressão "tudo isso aí", que encapsula todo o conteúdo mencionado anteriormente. Os outros cinco informantes responderam que o campo semântico de pecuária foi a pista que permitiu a identificação da relação. As respostas dos informantes a essa pergunta sugerem, portanto, dois tipos de sinais: textuais (referência anafórica, investigada por Fox (1987)), e cognitivos (modelos que ativam conhecimentos armazenados na memória de longo prazo).

\section{Excerto 4}

Pegam uma sementinha da soja,

(1) começam a manipular,

(2) manipular,

(3) manipular,

(4) manipular a sementinha da soja,

e começam a plantar soja em regiões de clima hostil.

No excerto 4, a relação que se estabelece entre as porções textuais é a relação de reafirmação multinuclear. Como se pode observar na definição (quadro 4), essa relação é realizada pela repetição, importante estratégia utilizada pelos falantes para organizar o discurso e garantir coerência. De acordo com Marcuschi (2006), embora possa parecer que a repetição poderia prejudicar a progressão tópica, esse fenômeno na realidade atua sobre a coesão e a continuidade tópica. 
$\mathrm{Na}$ análise de Antonio \& Cassim (2012: 88), apresentada no diagrama 5, uma mesma forma verbal (manipular) é repetida nas unidades de 2 a 5. Pode-se apontar uma motivação icônica para a repetição dessa forma verbal, uma vez que a reiteração sugere que a manipulação da semente de soja teve alguma duração. A relação de sequência é estabelecida no nível mais alto da estrutura retórica da porção textual do diagrama por haver sucessão cronológica entre os núcleos.

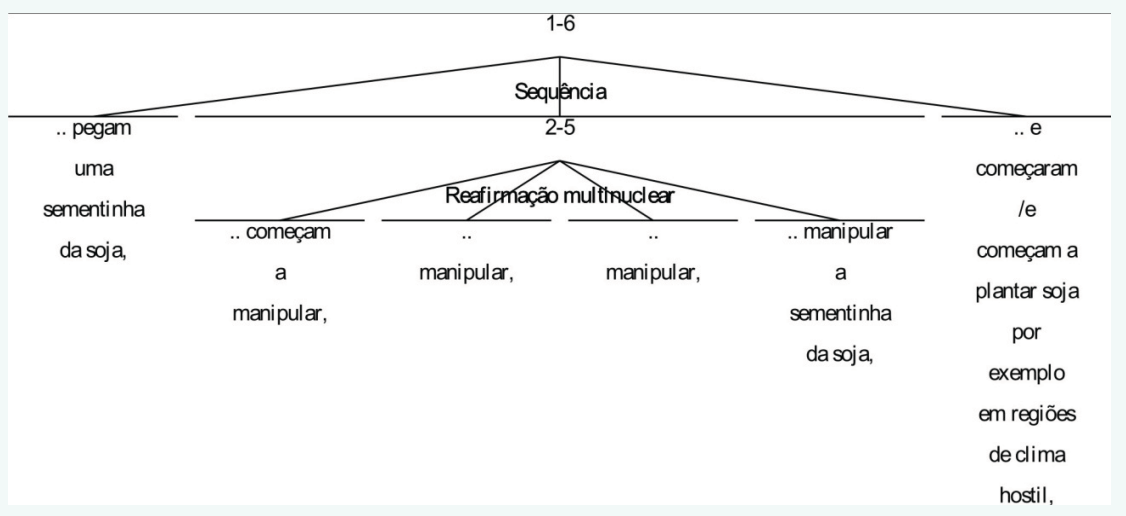

Diagrama 5 - Relação de reafirmação multinuclear.

Quadro 4 - Definição da relação de reafirmação multinuclear (Mann \& Taboada, 2010)

\begin{tabular}{|l|l|l|}
\hline $\begin{array}{l}\text { Nome da } \\
\text { relação }\end{array}$ & Condições em cada par de N & Intenção do falante \\
\hline $\begin{array}{l}\text { Reafirmação } \\
\text { multinuclear }\end{array}$ & $\begin{array}{l}\text { Um elemento constitui, em primeiro lugar, } \\
\text { a repetição de outro, com o qual se encontra } \\
\text { relacionado; os elementos são de importância } \\
\text { semelhante para os propósitos do falante }\end{array}$ & $\begin{array}{l}\text { O destinatário reco- } \\
\text { nhece a repetição por } \\
\text { meio dos elementos } \\
\text { relacionados }\end{array}$ \\
\hline
\end{tabular}

Ao serem questionados a respeito da função da repetição no excerto, nove informantes afirmaram que o produtor do texto utilizou a repetição para salientar a duração do processo de manipulação das sementes de soja. Apenas um informante não identificou a função da repetição, fazendo apenas uma interpretação do conteúdo das porções textuais. A repetição e as demais estratégias de construção do texto falado, como, por exemplo, a inserção parentética, a correção e o parafraseamento, de acordo com Antonio \& Cassim (2012), sinalizam relações retóricas na língua falada. 
Excerto 5

Antigamente no Brasil era assim: você chegava e pegava a terra, não tinha lei.

(1) Você vencia os índios,

(2) ficava com a terra pra você.

Ao serem indagados a respeito do excerto 5 (diagrama 6, caso de parataxe condicional), todos os informantes identificaram relação de causa-consequência ou de condição (cf. definição no quadro 5). As respostas corroboram a afirmação de Neves (2000) de que as construções concessivas, as construções causais e as construções condicionais situam-se em um mesmo contínuo semântico. De acordo com a autora, há um extremo em que a relação de causa é afirmada (construções causais), um extremo em que o vínculo causal entre as orações é negado (construções concessivas) e um espaço intermediário em que a relação de causa entre as orações é hipotetizada (condicionais).

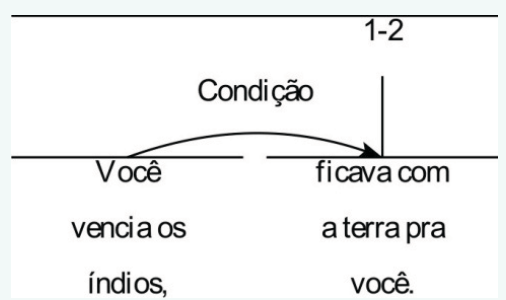

Diagrama 6 - Relação de condição estabelecida por construção paratática condicional.

Quadro 5 - Definição da relação de condição (Mann \& Taboada, 2010)

\begin{tabular}{|l|l|l|l|}
\hline $\begin{array}{l}\text { Nome da } \\
\text { relação }\end{array}$ & $\begin{array}{l}\text { Restrições sobre o núcleo } \\
\text { ou sobre o satélite indivi- } \\
\text { dualmente }\end{array}$ & $\begin{array}{l}\text { Restrições sobre } \\
\text { núcleo + satélite }\end{array}$ & $\begin{array}{l}\text { Intenção do } \\
\text { falante }\end{array}$ \\
\hline Condição & $\begin{array}{l}\text { Sobre S: S apresenta uma } \\
\text { situação não realizada hi- } \\
\text { potética, futura (relativa ao } \\
\text { contexto situacional de S). }\end{array}$ & $\begin{array}{l}\text { A realização de N } \\
\text { depende da realiza- } \\
\text { ção de S. }\end{array}$ & $\begin{array}{l}\text { O destinatário } \\
\text { reconhece como } \\
\text { a realização de } \\
\text { N depende da } \\
\text { realização de S. }\end{array}$ \\
\hline
\end{tabular}

No que diz respeito aos sinais utilizados para identificação da relação, cinco informantes afirmaram que a interdependência entre 
os estados-de-coisas ${ }^{3}$ e a ordem em que as orações se apresentam na construção possibilitaram a identificação. Três informantes fizeram referência ao próprio conteúdo das orações. Pode-se, no entanto, considerar que o conteúdo a que eles se referem também está relacionado à interdependência entre os estados-de-coisas. Um informante afirmou que o tempo verbal (pretérito imperfeito) foi a pista utilizada, e outro informante parafraseou a construção iniciando-a com o conectivo se para identificar a relação de condição.

A alta frequência de respostas indicando a interdependência entre os estados-de-coisas revela o reconhecimento, por parte dos informantes, de duas categorias que caracterizam as orações condicionais: factualidade e pressuposição.

A factualidade tem a ver com o valor de verdade e é um parâmetro que dinstingue orações factuais e orações não-factuais: uma oração factual descreve "uma propriedade ou relação como aplicável; um estado-de-coisas como real; um conteúdo proposicional como verdadeiro; um ato-de-fala como assertivo" (Quintero, 2002: 53).

Segundo Quintero (2002), a pressuposição é um parâmetro pragmático, uma vez que é a avaliação que o falante faz da informação que ele julga que seu destinatário tenha. É aplicada com outros parâmetros como tipo de entidade e factualidade. Assim,

No domínio factual, a pressuposição implica factividade, a pressuposição de que um evento é real (segunda ordem) ou de que um conteúdo proposicional é verdadeiro (terceira ordem). No domínio não-factual, a pressuposição implica contrafactividade, a pressuposição de que um evento é irreal ou de que um conteúdo proposicional é falso ${ }^{4}$ (p. 57).

Nove informantes-alunos identificaram a relação de causa-consequência ou de condição, sendo que quatro parafrasearam a estrutura

3. De acordo com Hengeveld (1998: 345), um estado-de-coisas "pode ser localizado no espaço e no tempo e pode ser avaliado em termos de sua realidade".

4. In the Factual domain, presupposition implies factivity, the presupposition that na event is real (second order) or that a propositional content is true (third order). In the Non-factual domain, presupposition implies counter-factivity, the presupposition that na event is unreal or that a propositional content is false. 
com o conectivo se, três apontaram o conteúdo das orações e dois a interdependência entre os estados-de-coisas.

Excerto 6

(1) Aí eu posso interferir então naquela fórmula

(2) diminuindo a velocidade de sedimentação.

Excerto 7

(1) Essa célula cancerígena perde o controle, o organismo não tem mais controle sobre ela e ela começa a se proliferar de forma desordenada,

(2) formando o melanoma.

Nos excertos 6 e 7, as relações se estabelecem em construções nas quais há uma oração adverbial gerundial. As orações reduzidas (em oposição às desenvolvidas, que têm forma verbal finita) são as que não são introduzidas por conectivo subordinativo e apresentam forma verbal não-finita (ou nominal, na terminologia tradicional): infinitivo, particípio ou gerúndio (Cunha \& Cintra, 1985).

Segundo Said-Ali $(1965)^{5}$, o português herdou do latim a forma ablativa do gerúndio, terminando em-ando,-endo ou-indo, de acordo com a conjugação do verbo. O renomado gramático descreve o uso de orações reduzidas de gerúndio com valor de oração subordinada adjetiva e com valor de oração subordinada adverbial. Neste último caso, o autor destaca a possibilidade de expressar "variedade de relações e cirscunstâncias" (p. 354-361). Dentre essas "relações e circunstâncias", Said Ali menciona circunstâncias temporais (simultaneidade, anterioridade e posterioridade), relações de causa e efeito, modo, meio ou instrumento, condição, concessão.

Braga (2002), em estudo a respeito das orações de gerúndio no português falado no Brasil, referenda as descrições das gramáticas tradicionais no que diz respeito aos tipos de relações semânticas codificadas por essas orações. No corpus investigado pela autora, foram encontradas relações aditivas, adjetivas, causais, concessivas, condicionais, consequenciais, modais, temporais e temporais-condicionais. No entanto, segundo a autora, "a identificação da relação semântica codificada pelas orações de gerúndio é muitas vezes problemática, já 
que elas tendem a favorecer a superposição de relações proposicionais" (p. 242).

No excerto 6, a relação de meio emerge da combinação entre as orações. A definição da relação de meio é apresentada no quadro 6.

Quadro 6 - Definição da relação retórica de meio (Mann \& Taboada, 2010)

\begin{tabular}{|l|l|l|l|}
\hline $\begin{array}{l}\text { Nome da } \\
\text { relação }\end{array}$ & $\begin{array}{l}\text { Restrições sobre } \\
\text { N ou sobre } \mathbf{S} \\
\text { individualmente }\end{array}$ & $\begin{array}{l}\text { Restrições sobre } \\
\mathbf{N}+\mathbf{S}\end{array}$ & $\begin{array}{l}\text { Intenção do falante/es- } \\
\text { critor }\end{array}$ \\
\hline Meio & $\begin{array}{l}\text { Sobre N: uma } \\
\text { atividade }\end{array}$ & $\begin{array}{l}\text { S apresenta um mé- } \\
\text { todo ou instrumento } \\
\text { que tende a fazer a } \\
\text { realização de N mais } \\
\text { provável }\end{array}$ & $\begin{array}{l}\text { O destinatário reconhece que } \\
\text { o método ou instrumento em } \\
\text { de N mais provável }\end{array}$ \\
\hline
\end{tabular}

Em sua pesquisa sobre as orações adverbiais nas línguas europeias, Hengeveld (1998) considera que as orações de meio são constituídas por entidades da ordem zero, ou seja, que não têm existência independente. É o que ocorre no excerto 6 (diagrama 7), em que a oração gerundial funciona como modificadora de uma propriedade da oração principal, de acordo com Antonio (2012: 68).

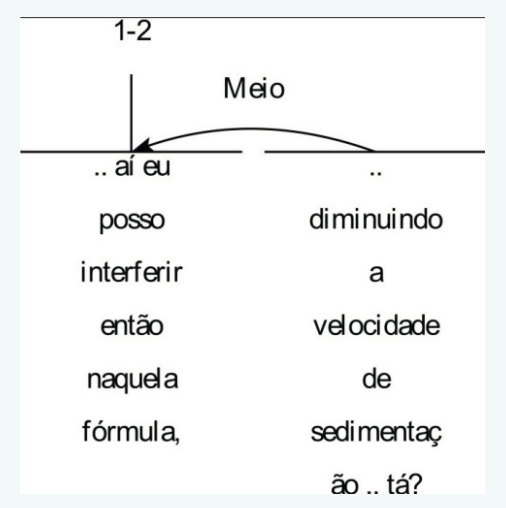

Diagrama 7 - Relação de meio estabelecida por oração adverbial gerundial 
Apenas dois informantes identificaram a relação de meio, caracterizando-a como maneira ou modo. Os demais informantes forneceram respostas não-plausíveis para o excerto, como causa-consequência, explicação, solução e condição. Dessa forma, atribui-se essa dificuldade dos informantes na identificação da relação à superposição de relações que podem ser sinalizadas pelo gerúndio, conforme afirma Braga (2002).

No que diz respeito ao excerto 7 , a relação que emerge entre as orações é a de resultado, conforme análise de Antonio (2012: 73). A relação de resultado é uma das relações que pertencem ao domínio semântico da causa. Como pode ser observado na definição (quadro 7), o evento do satélite é causado pelo evento do núcleo. Em termos de organização textual e fluxo de informação, o produtor do texto considera que o evento que está no núcleo é mais central para que atinja seus propósitos comunicativos. Quando a situação se inverte, ou seja, quando o evento que está no satélite causa o evento que está no núcleo, a relação é de causa. Na ocorrência do excerto 7 , o evento não foi causado voluntariamente, motivo pelo qual a relação de que se trata aqui é a de resultado não-volitivo (no rol da RST também há a relação de resultado volitivo).

Quadro 7 - Definição da relação de resultado (Mann \& Taboada, 2010)

\begin{tabular}{|l|l|l|l|}
\hline Nome da relação & $\begin{array}{l}\text { Restrições sobre } \\
\text { o núcleo ou sobre } \\
\text { o satélite indivi- } \\
\text { dualmente }\end{array}$ & $\begin{array}{l}\text { Restrições sobre N } \\
+\mathbf{S}\end{array}$ & $\begin{array}{l}\text { Intenção do } \\
\text { falante }\end{array}$ \\
\hline Resultado & $\begin{array}{l}\text { Sobre S: S não é } \\
\text { uma ação volitiva. }\end{array}$ & $\begin{array}{l}\text { N causou S; a apre- } \\
\text { sentação de N é mais } \\
\text { central do que a apre- } \\
\text { sentação de S para os } \\
\text { propósitos do falante. }\end{array}$ & $\begin{array}{l}\text { O destinatário re- } \\
\text { conhece que N po- } \\
\text { situação em S. }\end{array}$ \\
\hline
\end{tabular}

No estudo de Hengeveld (1998) sobre as orações adverbiais nas línguas da Europa, as orações de causa são constituídas por elementos de segunda ordem (estados-de-coisas). No excerto 7 (diagrama 8), o evento da unidade 4 é causado pelos eventos das unidades 1-3, ou seja, trata-se de estados-de-coisas, o que pode ser comprovado por meio dos testes propostos por Hengeveld \& Mackenzie (2008). Uma possi- 
bilidade é incluir um modificador de lugar de ocorrência: "formando o melanoma, o câncer de pele, no local afetado". Também pode ser incluído um modificador de tempo relativo de ocorrência: "formando o melanoma, o câncer de pele, após muita exposição ao sol".

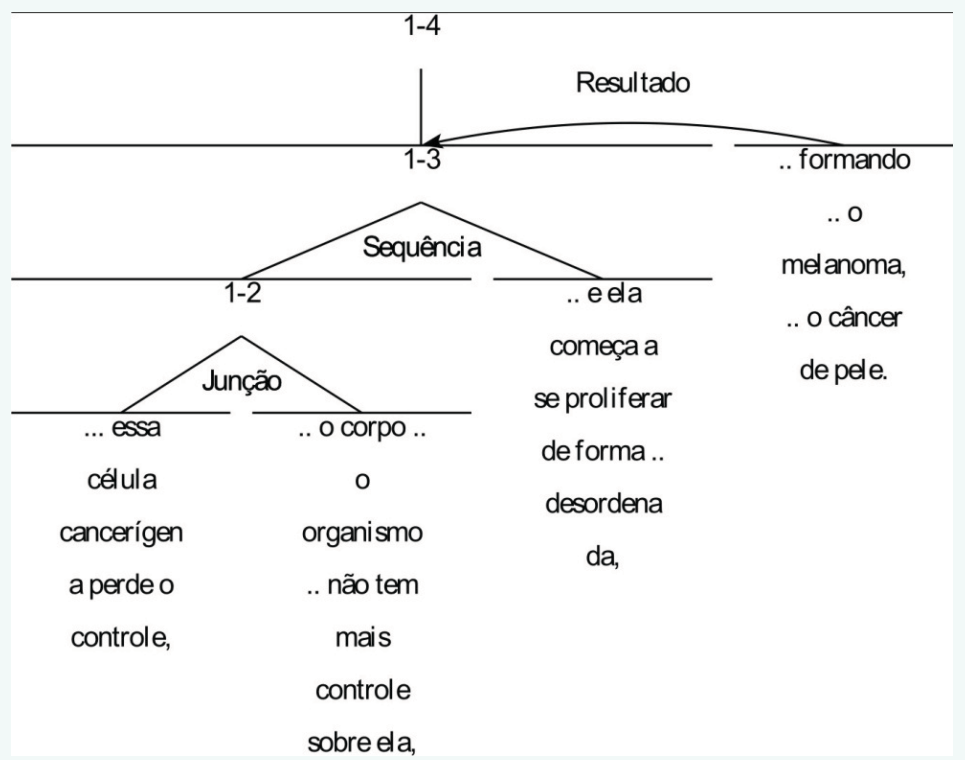

Diagrama 8 - Relação de resultado estabelecida por oração adverbial gerundial.

Sete informantes identificaram corretamente a relação de resultado, caracterizando-a como causa-consequência, ao passo que três informantes deram uma resposta não-plausível, explicação. De acordo com os informantes, ao contrário do que aconteceu com o excerto 6 , a identificação da relação foi possibilitada pela interdependência entre os estados-de-coisas codificados pelas orações.

Excerto 8

(1) Até esse ano que passou, eu corrigia os relatórios,

(2) devolvia pra vocês refazerem.

No excerto 8, a relação de sequência emerge da combinação entre as porções de texto (diagrama 9). Como pode ser observado na definição da relação (quadro 8), há sucessão temporal entre os eventos dos núcleos. 


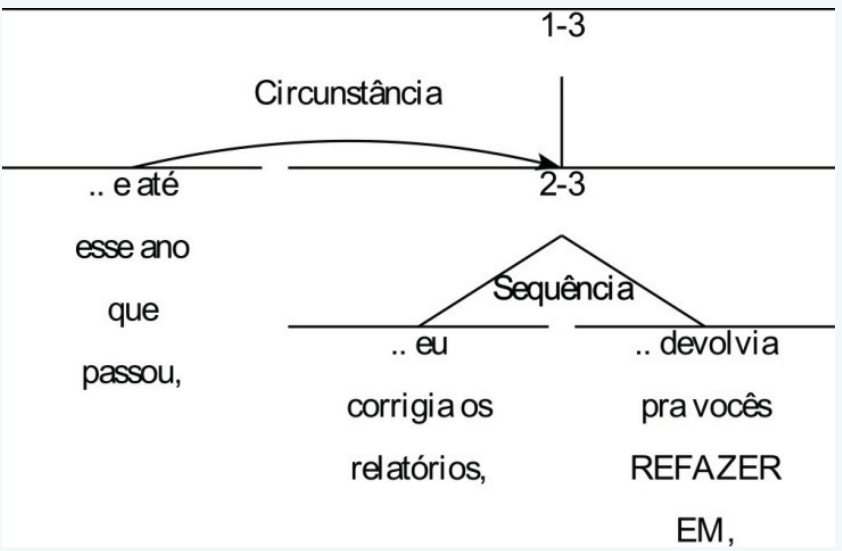

Diagrama 9 - Relação de sequência.

Quadro 8 - Definição da relação de sequência (Mann \& Taboada, 2010)

\begin{tabular}{|l|l|l|}
\hline $\begin{array}{l}\text { Nome da } \\
\text { relação }\end{array}$ & Condições em cada par de N & Intenção do falante \\
\hline Sequência & $\begin{array}{l}\text { Existe uma relação de sucessão entre as } \\
\text { situações apresentadas nos núcleos }\end{array}$ & $\begin{array}{l}\text { O destinatário reconhece as } \\
\text { relações de sucessão entre os } \\
\text { núcleos. }\end{array}$ \\
\hline
\end{tabular}

Seis informantes identificaram corretamente a relação de sequência. Esses informantes mencionaram que a pista utilizada estava no conteúdo do texto, ou seja, um evento era anterior ao outro. Também mencionaram a expressão temporal "até esse ano que passou" e o tempo verbal dessa oração como pista. Os outros quatro informantes forneceram respostas não-plausíveis para o excerto, como, por exemplo, condição, consequência, correção. Na análise das respostas fornecidas pelos informantes a esse excerto, observam-se, portanto, dois tipos de pistas: o conteúdo do próprio texto (Ford, 2000) e expressões temporais e o tempo verbal (Taboada, 2009).

Excerto 9

(1) O organismo heterotrófico não produz seu próprio alimento,

(2) tem que obter esse alimento do meio.

No excerto 9, a relação de reformulação núcleo-satélite (quadro 9) emerge da combinação entre as porções textuais. Na ocorrência anali- 
sada (diagrama 10), o falante faz uma reformulação da porção textual anterior. Trata-se, portanto, de um caso de parafraseamento, estratégia na qual o falante usa o discurso anterior como matriz para o novo enunciado. De acordo com Fávero, Andrade, \& Aquino (2006), deve haver equivalência semântica entre o enunciado matriz e a paráfrase e, segundo Hilgert (2006), o parafraseamento ajuda o falante a encontrar o vocábulo ou expressão mais apropriados para o conteúdo que deseja veicular.

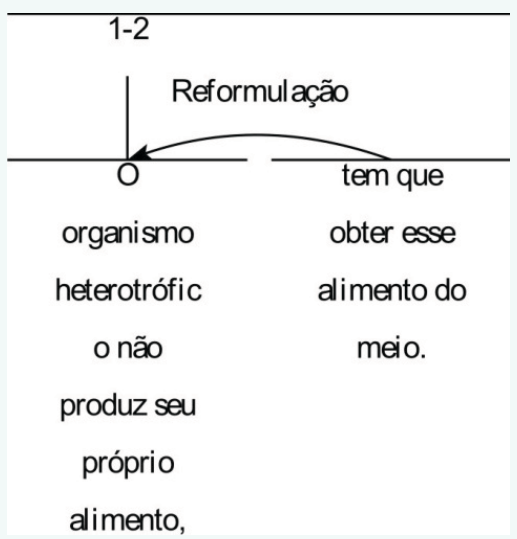

Diagrama 10 - Relação de reformulação núcleo-satélite.

Quadro 9 - Definição da relação de reformulação núcleo-satélite (Mann \& Taboada, 2010)

\begin{tabular}{|l|l|l|l|}
\hline Nome da relação & $\begin{array}{l}\text { Restrições sobre } \\
\text { o núcleo ou sobre } \\
\text { o satélite indivi- } \\
\text { dualmente }\end{array}$ & $\begin{array}{l}\text { Restrições sobre } \\
\text { núcleo + satélite }\end{array}$ & $\begin{array}{l}\text { Intenção do } \\
\text { falante }\end{array}$ \\
\hline $\begin{array}{l}\text { Reformulação } \\
\text { núcleo-satélite }\end{array}$ & Não há. & $\begin{array}{l}\text { S reformula N, onde S } \\
\text { e N possuem um peso } \\
\text { semelhante; N é mais } \\
\text { central para alcançar } \\
\text { os objetivos do falan- } \\
\text { te do que S }\end{array}$ & $\begin{array}{l}\text { O destinatário re- } \\
\text { conhece S como } \\
\text { reformulação }\end{array}$ \\
\hline
\end{tabular}

Oito informantes identificaram a função reformuladora do satélite, afirmando que o satélite explicava o conteúdo do núcleo. Quatro desses informantes afirmaram que utilizaram o conteúdo das porções textuais como pista para a identificação da relação, ao passo que três deles foram mais específicos e disseram que o verbo modal deôntico "ter que" foi a pista determinante para a identificação. Um desses informantes que 
identificaram a relação de reformulação não indicou que pista utilizou. Os outros dois informantes identificaram a relação como sendo de causa-consequência, que é perfeitamente plausível para o excerto em análise. Para esses informantes, que se pautaram no conteúdo do texto para a identificação da relação, ter que obter alimento do meio é consequência de não se produzir seu próprio alimento.

\section{Excerto 10}

Louis Pasteur é um grande laboratorista, tem um monte de instrumentos de laboratório que tem o nome dele. Então ele sabia dominar essa técnica de vidraria.

O que ele fez?

(1) Ele pegou um balão, colocou um caldo nutritivo ali, um meio de cultura.

(2) Já viram quando vai fazer o senhor bactéria? Não pega o cotonete, passa numa gelatininha, um meio de cultura? Só que no caso ali era líquido.

Pegou esse meio de cultura, colocou no balão, esquentou a boca desse balão e torceu ele, formando o pescoço do cisne.

No excerto 10, a relação parentética emerge da combinação entre as porções textuais. De acordo com Jubran (2006), inserções parentéticas são desvios do tópico discursivo. Trazem informação paralela sobre o conteúdo do tópico discursivo, sobre a expressão linguística do tópico discursivo ou sobre o contexto comunicativo. Embora as inserções parentéticas possam parecer desviantes no que diz respeito ao tópico discursivo, elas estão, na realidade, 'amarradas' ao tópico por trazerem informação que é considerada pelo falante essencial para a compreensão do assunto. A relação parentética não está presente no rol de relações clássicas da RST (Mann \& Thompson, 1988), mas foi definida posteriormente (quadro 10). Pardo (2005) afirma que o efeito dessa relação é que o destinatário reconheça que $\mathrm{S}$ apresenta informação extra referente a $\mathrm{N}$ complementando N. Na ocorrência do excerto 10, o professor utiliza o satélite parentético para exemplificar para os alunos como Louis Pasteur realizou uma experiência. Para isso, menciona o "senhor bactéria", que ele pressupõe que os alunos conheçam dos programas de televisão. Terminado o conteúdo parentético, o professor retoma o fluxo do que vinha explicando por meio da relação de retomada. 
Quadro 10 - Definição da relação parentética (Pardo, 2005: 140)

\begin{tabular}{|l|l|l|l|}
\hline $\begin{array}{l}\text { Nome da } \\
\text { relação }\end{array}$ & $\begin{array}{l}\text { Restrições sobre N } \\
\text { ou sobre S individu- } \\
\text { almente }\end{array}$ & $\begin{array}{l}\text { Restrições sobre N } \\
+ \text { S }\end{array}$ & $\begin{array}{l}\text { Intenção do falante/ } \\
\text { escritor }\end{array}$ \\
\hline Parentética & $\begin{array}{l}\text { Sobre N: não há. } \\
\text { Sobre S: apresenta } \\
\text { informação extra re- } \\
\text { lacionada a N que não } \\
\text { está expressa no fluxo } \\
\text { principal do texto. }\end{array}$ & $\begin{array}{l}\text { S apresenta informa- } \\
\text { ção extra relacionada a a }\end{array}$ & $\begin{array}{l}\text { O destinatário pertence ao fluxo } \\
\text { principal do texto. } \\
\text { nhece que S apresenta } \\
\text { informação extra rela- } \\
\text { cionada a N, comple- } \\
\text { mentando N. }\end{array}$ \\
\hline
\end{tabular}

Nove informantes identificaram de alguma forma a função do satélite parentético, seja para introduzir uma explicação mais próxima do conhecimento dos alunos, seja para introduzir um exemplo. Apenas um informante forneceu uma resposta não-plausível, a relação de resultado. Novamente o conteúdo do texto (Ford, 2000) foi apresentado pela maioria dos informantes como pista responsável pela identificação da relação, ou seja, seis informantes se pautaram no conteúdo explícito das orações para determinarem a proposição relacional implícita. Três informantes não souberam informar que pista utilizaram para a identificação, e um informante afirmou que se pautou pela pontuação.

\section{Conclusões}

Este trabalho teve como objetivo investigar outros meios de sinalização das relações além de conectivos e MDs utilizados pelos destinatários do discurso para identificação das relações retóricas.

Utilizou-se o aparato teórico-metodológico da RST, (Rhetorical Structure Theory - Teoria da Estrutura Retórica), uma teoria descritiva que tem por objeto o estudo da organização dos textos, caracterizando as relações que se estabelecem entre as partes do texto.

A investigação foi realizada a partir da apresentação de dez excertos para alunos e professores de curso superior. Para cada excerto apresentado, os informantes responderam algumas perguntas para que se pudesse verificar se a relação retórica estabelecida entre as porções textuais que compõem o excerto foi reconhecida. 
Nos dez excertos apresentados aos informantes, as relações retóricas não são sinalizadas por conectores, mas por outros meios, como pontuação, correlação modo-temporal, conteúdo das porções textuais, paralelismo sintático, paráfrase, inserção parentética, repetição, apresentação de evidências etc, com a finalidade de verificar se os informantes reconheceriam essas relações por meio dessas outras pistas.

Procurou-se verificar se a falta de sinalização por meio de um MD ou conectivo impediria ou dificultaria a identificação da relação e também se os informantes saberiam explicitar outros meios além dos conectivos que servissem como pista para identificação da relação.

Após a análise, verificou-se que, em sua grande maioria, as relações retóricas foram identificadas pelos informantes, corroborando o pressuposto da RST de que as relações de coerência, por serem de sentido, e não de forma, podem ser estabelecidas e interpretadas independentemente de serem marcadas explicitamente por conectivos. As pistas indicadas pelos informantes para identificação das relações retóricas foram formais, como os sinais de pontuação, o modo da oração (pergunta-resposta); fonológicas, como a entonação utilizada na leitura; morfossintáticas, como tempo verbal, expressões adverbiais; semânticas, como a interdependência entre os estados-de-coisas, o próprio sentido das porções textuais envolvidas ou de palavras-chave nessas porções; textuais, como paralelismo nas construções, referência anafórica; cognitivas, como a ativação de referentes a partir de um modelo cognitivo global.

Recebido em setembro de 2014

Aprovado em outubro de 2015

E-mail: prof.jdantonio@gmail.com

\section{Referências bibliográficas}

Antonio, J. D. 2009. O texto como objeto de estudo na Linguística Funcional. In J. D. Antonio \& P. Navarro (eds.). O texto como objeto de ensino, de descrição lingüística e de análise textual e discursiva (p. 61-80). Maringá: Eduem.

. 2012. Relações retóricas estabelecidas por orações adverbiais gerundiais. Alfa, 56(1): 55-79. 
Antonio, J. D., \& F. T. R. CAssim. 2012. Coherence relations in academic spoken discourse. Linguistica LII: Le Discours Parlé, 52(1): 323336.

BragA, M. L. 2002. Processos de redução: o caso das orações de gerúndio. In I. G. V. Koch. Ed. Gramática do Português Falado: Desenvolvimentos (Vol. 6, p. 239-258). Campinas: Ed. da Unicamp.

Butler, C. S. 2003. Structure and function: a guide to three major structural-functional theories. Part I: approaches to the simplex clause. Amsterdam: John Benjamins.

Chafe, W. 1985. Linguistic differences produced by differences between speaking and writing. In: D. R. Olson, N. Torrance \& A. Hildyard (eds.). Literacy, Language and Learning: the nature and consequences of reading and writing (p. 105-123). Cambridge: Cambridge University Press.

Cunha, C. \& L. Cintra. 1985. Nova Gramática do Português Contemporâneo. (2 ed.) Rio de Janeiro: Nova Fronteira.

Du Bors, J. W. 1987. The Discourse Basis of Ergativity. Language, 63: 805-855.

FÁvero, L. L., M. L. C. V. O. Andrade, \& Z. G. O. D. Aquino. 2006. O par dialógico pergunta-resposta. In C. C. A. S. Jubran \& I. G. V. Koch (eds.). Gramática do Português Culto Falado no Brasil. V. I: Construção do Texto Falado (p. 133-166). Campinas: Ed. da Unicamp.

ForD, C. 2000. The treatment of contrasts in interaction. In: E. CouperKuhlen \& B. Kortman (eds.). Cause, condition, concession, contrast - cognitive and discourse perspectives (p. 283-312). Berlim: Mouton de Gruyter.

Fox, B. A. 1987. Discourse structure and anaphora: written and conversational English. Cambridge: Cambridge University Press.

Givón, T. 1983. Topic continuity in discourse: a quantitative crosslanguage study. Amsterdam: John Benjamins.

Gómez-GonzÁlez, M. L. Á. \& M. TABoAdA. 2005. Coherence Relations in Functional Discourse Grammar. In: J. L. Mackenzie \& M. L. Á. Gómez-González (eds.). Studies in Functional Discourse Grammar (p. 227-259). Berne: Peter Lang.

Grimes, J. 1975. The thread of discourse. Mounton: The Hague.

HENGEVELD, K. 1998. Adverbial clauses in the languages of Europe. In: J. Awera (ed.). Adverbial constructions in the languages of Europe (p. 335-419). Berlim: Mouton de Gruyter.

Hengeveld, K. \& J. L. Mackenzie. 2008. Functional Discourse Grammar. A typologically-based theory of language structure. Oxford: Oxford University Press. 
Hilgert, J. G. 2006. Parafraseamento. In: C. C. A. S. Jubran \& I. G. V. Koch (eds.). Gramática do Português Culto Falado no Brasil. V. I: Construção do Texto Falado (p. 255-273). Campinas: Ed. da Unicamp.

Hoвbs, J. R. 1985. On the coherence and structure of discourse. Stanford: Stanford University.

HoPper, P. \& S. A. ThOMPson. 1980. Transitivity in grammar and discourse. Language, 56(2): 252-299.

Jubran, C. C. A. S. 2006. Parentetização. In: C. C. A. S. Jubran \& I. G. V. Koch (eds.). Gramática do Português Culto Falado no Brasil. V. I: Construção do Texto Falado (p. 301-357). Campinas: Ed. da Unicamp.

Mann, W. C.; C. Matthiessen \& S. A. Thompson. 1992. Rhetorical Structure Theory and text analysis. In: W. C. Mann \& S. A. Thompson (eds.). Discourse description: diverse linguistic analyses of a fundraising text (p. 39-77). Amsterdam: John Benjamins.

Mann, W. C. \& M. Taboada. 2010. RST Web Site. Available: http://www. sfu.ca/rst19/09/2013].

Mann, W. C. \& S. A. Thompson. 1983. Relational Propositions in Discourse. Los Angeles: University of Southern California. . 1988. Rhetorical Structure Theory: toward a functional theory of text organization. Text, 8(3): 243-281.

Marcuschi, L. A. 2001. Da fala para a escrita: atividades de retextualização. São Paulo: Cortez.

. 2006. Repetição. In C. C. A. S. Jubran \& I. G. V. Koch (eds.). Gramática do Português Culto Falado no Brasil. V. I: Construção do Texto Falado (p. 219-254). Campinas: Ed. da Unicamp.

Matthiessen, C. \& S. A. Thompson. 1988. The structure of discourse and 'subordination'. In: J. Haiman \& S. Thompson (eds.). Clause Combining in Grammar and Discourse (p. 275-329). Amsterdam/ Philadelphia: J. Benjamins.

Neves, M. H. M. 1997. A Gramática Funcional. São Paulo: Martins Fontes.

2000. Gramática de Usos do Português. São Paulo: Ed. da Unesp.

Nichols, J. 1984. Functional theories of grammar. Annual review of Anthropology, 43(97-117).

Novaes-MARQues, N. B. 2014. A relação conclusiva na língua portuguesa: funções resumo, conclusão e consequência. Doutorado. Universidade Estadual Paulista Júlio de Mesquita Filho, São José do Rio Preto. 
Pardo, T. A. S. 2005. Métodos para Análise Discursiva Automática. Doutorado. Universidade de São Paulo, São Carlos.

Polany, L. 1986. The linguistic discourse model: towards a formal theory of discourse structure. Cambridge, MA: BBN Laboratories.

Quintero, M. J. P. 2002. Subordination in English: a functionalist approach. Amsterdam: Rodopi.

Risso, M. S.; Silva, G. M. O.; Urbano, H. 2002. Marcadores discursivos: traços definidores. In: Koch, I. G. V. (ed.). Gramática do português falado. V. VI: Desenvolvimentos (p. 21-57). Campinas: Ed. da Unicamp.

SaID-Ali, M. 1965. Gramática Histórica da Língua Portuguesa. (5 ed.) São Paulo: Melhoramentos.

Sanders, T. J. M.; W. P. M. Spooren \& L. G. M. Noordman. 1992. Toward a taxonomy of coherence relations. Discourse processes, 15: 1-35.

Schank, R. C. \& R. P. Abelson. 1977. Scripts, plans, gols and understanding. Hillsdale: Erlbaum.

TABOADA, M. 2006. Discourse Markers as Signals (or Not) of Rhetorical Relations. Journal of Pragmatics, 48(4): 567-592. .2009. Implicit and explicit coherence relations. In: J. Renkema (ed.). Discourse, of course (p. 125-138). Amsterdam: John Benjamins.

van DıJK, T. A. 1992. Cognição, discurso e interação. São Paulo: Contexto.

vAN DiJK, T. A. \& W. KINTSCH. 1983. Strategies of discourse comprehension. New York: Academic Press.

VAN VAlin, R. D. 2002. Functional Linguistics. In: M. Aronoff \& J. ReesMiller (eds.). The handbook of linguistics (p. 250-263). Malden: Blackwell Publishers. 